\title{
RESEARCH
}

\section{Inclusion of Health Disparities, Cultural Competence, and Health Literacy Content in US and Canadian Pharmacy Curriculums}

\author{
Aleda M. H. Chen, PharmD, PhD, ${ }^{a}$ Anastasia L. Armbruster, PharmD, ${ }^{b}$ Beth Buckley, PharmD, \\ Jennifer A. Campbell, PharmD, ${ }^{\mathrm{d}}$ Devra Khanh Dang, PharmD, ${ }^{\mathrm{e}}$ Radhika Devraj, PhD, ${ }^{\mathrm{fg}}$ \\ Imbi Drame, PharmD, ${ }^{\mathrm{h}}$ Akesha Edwards, PharmD, PhD, ${ }^{\mathrm{i}}$ Sally L. Haack, PharmD, ${ }^{\mathrm{j}}$ \\ Qing Ma, PharmD, PhD, ${ }^{\mathrm{k}}$ Natasha Petry, PharmD, ${ }^{1}$ Lourdes G. Planas, PhD, ${ }^{\mathrm{m}}$ \\ Cheryl A. Sadowski, PharmD, ${ }^{\mathrm{n}}$ Jennifer Santee, PharmD, ${ }^{\mathrm{o}}$ Latasha Wade, PharmD, ${ }^{\mathrm{p}}$ \\ Nancy Borja-Hart, PharmD ${ }^{\mathrm{q}}$ \\ ${ }^{a}$ Cedarville University, School of Pharmacy, Cedarville, Ohio \\ ${ }^{\mathrm{b}}$ St. Louis College of Pharmacy, St. Louis, Missouri \\ ${ }^{c}$ Concordia University, Wisconsin School of Pharmacy, Mequon, Wisconsin \\ ${ }^{\mathrm{d}}$ Manchester University, College of Pharmacy and Health Sciences, Fort Wayne, Indiana \\ ${ }^{\mathrm{e}}$ University of Connecticut, School of Pharmacy, Storrs, Connecticut \\ ${ }^{\mathrm{f}}$ Southern Illinois University Edwardsville, School of Pharmacy, Edwardsville, Illinois \\ ${ }^{g}$ Editorial Board Member, American Journal of Pharmaceutical Education, Arlington, Virginia \\ ${ }^{\mathrm{h}}$ Howard University, College of Pharmacy, Washington, District of Columbia \\ ${ }^{\mathrm{i}}$ University of Findlay, College of Pharmacy, Findlay, Ohio \\ ${ }^{j}$ Drake University, College of Pharmacy and Health Sciences, Des Moines, Iowa \\ ${ }^{\mathrm{k}}$ University at Buffalo, School of Pharmacy and Pharmaceutical Sciences, Buffalo, New York \\ ${ }^{1}$ North Dakota State University, School of Pharmacy, Fargo, North Dakota \\ ${ }^{\mathrm{m}}$ University of Oklahoma, College of Pharmacy, Oklahoma City, Oklahoma \\ ${ }^{\mathrm{n}}$ University of Alberta, Faculty of Pharmacy \& Pharmaceutical Sciences, Edmonton, Alberta, Canada \\ ${ }^{\circ}$ University of Missouri - Kansas City, School of Pharmacy, Kansas City, Missouri \\ ${ }^{\mathrm{p}}$ University of Maryland Eastern Shore, School of Pharmacy, Princess Anne, Maryland \\ ${ }^{\mathrm{q}}$ The University of Tennessee Health Science Center, College of Pharmacy, Nashville, Tennessee \\ Submitted May 29, 2020; accepted September 28, 2020; published January 2021.
}

Objective. To determine how US and Canadian pharmacy schools include content related to health disparities and cultural competence and health literacy in curriculum as well as to review assessment practices.

Methods. A cross-sectional survey was distributed to 143 accredited and candidate-status pharmacy programs in the United States and 10 in Canada in three phases. Statistical analysis was performed to assess inter-institutional variability and relationships between institutional characteristics and survey results.

Results. After stratification by institutional characteristics, no significant differences were found between the $72(50 \%)$ responding institutions in the United States and the eight (80\%) in Canada. A core group of faculty typically taught health disparities and cultural competence content and/or health literacy. Health disparities and cultural competence was primarily taught in multiple courses across multiple years in the pre-APPE curriculum. While health literacy was primarily taught in multiple courses in one year in the pre-APPE curriculum in Canada $(75.0 \%)$, delivery of health literacy was more varied in the United States, including in a single course $(20.0 \%)$, multiple courses in one year $(17.1 \%)$, and multiple courses in multiple years (48.6\%). Health disparities and cultural competence and health literacy was mostly taught at the introduction or reinforcement level. Active-learning approaches were mostly used in the United States, whereas in Canada active learning was more frequently used in teaching health literacy $(62.5 \%)$ than health disparities and cultural competence (37.5\%). Few institutions reported providing professional preceptor development.

Conclusion. The majority of responding pharmacy schools in the United States and Canada include 


\section{American Journal of Pharmaceutical Education 2021; 85 (1) Article 8200.}

content on health disparities and cultural competence content and health literacy to varying degrees; however, less is required and implemented within experiential programs and the co-curriculum. Opportunities remain to expand and apply information on health disparities and cultural competence content and health literacy content, particularly outside the didactic curriculum, as well as to identify barriers for integration.

Keywords: health disparities, cultural competence, health literacy, curricular integration

\section{INTRODUCTION}

Racial and ethnic diversity continue to increase in the United States and Canada. According to recent projections by the US Census Bureau, $56.4 \%$ of Americans will belong to a racial or ethnic minority group by 2044 and almost $20 \%$ will be foreign born by $2060 .{ }^{1}$ Similar trends exist in Canada, where an estimated 30\% of Canada's population will be immigrants by $2036 .^{2-4}$ Recognizing that racial and ethnic minority populations experience high rates of health disparities, the US Department of Health and Human Services created an action plan to provide guidance in this area. ${ }^{2}$ One of the goals is to "increase the diversity and cultural competency of clinicians" so they are prepared to appropriately incorporate cultural factors into the patient encounter. Along with culture, low health literacy can also negatively impact health outcomes. ${ }^{3}$ Approximately 90 million people in the United States and 9 million people in Canada experience limited literacy. ${ }^{4,5}$ Low health literacy disproportionately affects racial and ethnic minorities. ${ }^{6}$

In Canada, the Minister of Health's 2019 mandate letter provides direction to support improved research and care regarding diversity, specifically racial diversity. ${ }^{7}$ Indigenous healthcare has received an increased focus since 2015 when the Truth and Reconciliation Commission (TRC) of Canada published 94 Calls to Action. Call to Action 24 requires that students in the health sciences take a course "dealing with Aboriginal health issues, including the history and legacy of residential schools, the United Nations Declaration on the Rights of Indigenous Peoples, Treaties and Aboriginal rights, and Indigenous teachings and practices. This will require skills-based training in intercultural competency, conflict resolution, human rights, and anti-racism.,"

As the United States and Canadian populations become more diverse, student pharmacists must be prepared to deliver culturally responsive healthcare. Preparation must extend beyond understanding the impact of race and ethnicity on health disparities and provider-patient relationships to a broader conceptualization of the diverse set

Corresponding Author: Aleda M. H. Chen, Cedarville University, School of Pharmacy, 251 N. Main St., Cedarville, OH 45314. Tel: 937-766-7454. Email: amchen@

cedarville.edu of patient backgrounds that can influence decisionmaking and care, such as religion, health beliefs, age, gender identity, sexual orientation, income level, (dis) ability status, and immigration status. Not only is this important for providing patient-centered care, it is also necessary for recognizing, addressing, and decreasing health disparities. Various publications recommend integrating health disparities and cultural competence education and training into pharmacy curricula. ${ }^{9,10}$ The Association of Faculties of Pharmacy of Canada (AFPC) Education Outcomes specifically reference the TRC and encourage a high priority on Call to Action 24 to be placed in curricula. ${ }^{11}$ The Accreditation Council for Pharmacy Education (ACPE) standards highlight the responsibility of programs to prepare graduates who can recognize social determinants of health (Standard 3). The ACPE standards also list cultural awareness as a required element of the didactic curriculum. ${ }^{12}$ The American Association of Colleges of Pharmacy (AACP) Center for the Advancement of Pharmacy Education (CAPE) outcomes note the importance of graduates' ability to modify communication strategies to meet patient needs and incorporate patient beliefs into care plans. ${ }^{13}$ Although multiple entities recommend inclusion of these topics and some accrediting bodies require them, there is little direction on how pharmacy schools should incorporate this content or subsequently assess student learning.

A 2007 study by Onyoni and Ives examined the degree to which cultural competency concepts were incorporated into the organizational structure and curricula of accredited colleges and schools of pharmacy in the United States and Canada. ${ }^{14}$ Their study found that didactic and case-based instruction were the prevailing pedagogical approaches for cultural competency education and training. While more than half of the responding schools affirmed revisions to their curricula in the past to include topics related to cultural competency, 49\% expressed intent to add new courses and topics. ${ }^{14}$ Since then, more than 30 new schools have been established in the United States, yet no additional large-scale surveys of cultural competency education and training in curricula have been performed.

While health literacy education has been examined in discrete courses taught in individual schools, ${ }^{15-17}$ there 


\section{American Journal of Pharmaceutical Education 2021; 85 (1) Article 8200.}

has never been a comprehensive national assessment of scope of health literacy content delivery in the United States or Canada. The purpose of this study was to determine how schools and colleges of pharmacy in the United States and Canada include content related to health disparities and cultural competence and health literacy in both their curriculum and assessment practices.

\section{METHODS}

This cross-sectional study was conducted using an electronic survey. Faculty investigators from 16 schools and colleges of pharmacy convened to develop the survey through consensus. They initially met in four subgroups to identify didactic curriculum questions, experiential curriculum questions, patient populations that should be covered within health disparities and cultural competence and health literacy curricula, and institutional characteristics to request in the survey. The subgroups met as a large group four additional times in spring 2019 to collate and edit survey questions. Survey questions were then piloted at each investigator's institution to ensure clarity and easy navigation and to inform final edits.

The workgroup used the domains listed in the Tool for Assessing Cultural Competence Training (TACCT) to develop questions regarding what cultural competency content schools cover. ${ }^{18,19}$ The TACCT serves as a validated resource of health disparities and cultural competence content inclusion ${ }^{18,19}$ and is recommended for use. ${ }^{9,10}$ Questions related to health literacy content covered by schools were based on overall reviews of published literature on HL and literature highlighting techniques and tools for patient-centered communication and health literacy assessment, such as the Pharmacy Health Literacy Center within the Agency for Healthcare Research and Quality (AHRQ). ${ }^{30}$ A specific process for searching pre-specified terms and databases was not used. Additionally, the study team, which included faculty members from 16 schools, offered input based on topics covered within their respective programs. These questions were designed to parallel items in the cultural competence portion of the survey.

The finalized survey (available upon request) included all identifiable areas of pharmacy curricula; it sought to identify the breadth and depth, ie, introduction, reinforcement, and mastery of health disparities and cultural competence and health literacy teaching that exists in accredited pharmacy programs across the United States and Canada. At the outset, common terms and abbreviations, such as health literacy, didactic curriculum, interprofessional education, and introduction/reinforcement/mastery were defined for respondents to refer to as needed. Survey respondents were not required to respond to all items. The survey contained the following four sections: Content and Delivery: timing and type of content delivered in didactic, pre-advanced pharmacy practice experience (APPE) curricula (four items); Active Learning, Topics and Populations: use and type of activelearning strategies, as well as populations covered (seven items); Faculty: level of faculty involvement in content delivery (one item); Experiential: type of content incorporated into introductory and advances pharmacy practice experiences, as well as preceptor development (four items).

The survey was distributed using a modified Dillman approach $^{20}$ across three phases in the United States and Canada using Qualtrics (Provo, UT). Phase 1 took place in May and June 2019. The survey was distributed to 143 accredited and candidate status pharmacy programs in the United States and 10 Canadian pharmacy programs. Phase 2 began in June 2019 and continued until August. In this study phase, a member of the research team telephoned or e-mailed each school that had not responded to the survey during phase 1. Emails contained a personal greeting, survey invitation language, a study reminder, and the electronic survey link. In August 2019, phase 3 of data collection was completed, with a final reminder distributed only to non-responders.

Individuals were identified as being predominantly responsible for the management and/or delivery of health disparities and cultural competence and health literacy content within the curriculum for each respective pharmacy program using a Google form sent via AACP listservs or the institutional website. These individuals received the survey for their institution. If a key person was not identified, the survey was sent to an assessment and/or academic affairs administrator, who was asked to identify the appropriate person to complete the survey. Institutional Review Board approval was received from all 16 institutions collaborating on this investigation.

Data were analyzed using SPSS, version 26.0 (IBM, Armonk, NY). Descriptive statistics were performed for institutional demographics and characteristics related to student population, geographical location, and private vs public status. Chi-square tests were used for nominal or ordinal data to assess inter-institutional variability and relationships between institutional characteristics and survey results.

\section{RESULTS}

Seventy-two of the $143(50.3 \%)$ US schools and colleges and eight of the $10(80 \%)$ Canadian schools and colleges participated in the survey, for an overall response rate of $52.3 \%$. However, not all respondents answered all questions, as noted in the tables. Over half of participating 


\section{American Journal of Pharmaceutical Education 2021; 85 (1) Article 8200.}

US schools were private $(n=41,56.9 \%)$, four were historically Black colleges and universities (HBCU, 5.6\%), and four were Hispanic-serving institutions (HSI, 5.6\%). All Canadian schools were public, not faith-based, and had no designations (Table 1).

Health disparities and cultural competence (HDCC) and health literacy (HL) were typically taught across institutions by less than $25 \%$ of the faculty members at that school or college (Table 1). Primarily, HDCC was taught in multiple courses across multiple years in the pre-APPE curriculum. Health literacy was primarily taught in multiple courses in one year in the pre-APPE curriculum in Canada. In the United States, approaches to delivery of HL content were more varied and included providing a single course, multiple courses in one year, and multiple courses in multiple years (Table 2).

Concerning the breadth of HDCC content, more than $50 \%$ of US institutions taught six of the seven TACCT domains, with the least frequently taught domain being the use of interpreters (Table 3). Regarding depth, most
HDCC content was taught at the introductory level (24.6\%-54.7\%) or reinforcement level (20.3\%-67.7\%) rather than the mastery level (1.6\%-21.5\%). Less than $30 \%$ of schools incorporated the use of interpreters, and when incorporated, it was most often at the introductory level (54.7\%). In Canada, six of the seven HDCC domains were taught by $50 \%$ or fewer of schools at the introductory level (12.5\%-50\%) or reinforcement level (12.5\%$62.5 \%)$. The most commonly taught domain (62.5\%) was self-reflection/culture of pharmacy (eg, addressing the power imbalance between provider and patient and addressing personal bias) (Table 3).

Regarding health literacy content breadth, most US institutions taught all health literacy topics. The highest level at which most content was taught was introductory or reinforcement (Table 3). Plain language/clear communication of oral/verbal strategies and written strategies was taught consistently at the higher levels (reinforcement $42.2 \%-48.4 \%$ and mastery $15.6 \%-20.3 \%$ ). In Canada, more than $50 \%$ of schools taught most of the health

Table 1. Characteristics of Schools and Colleges of Pharmacy Represented in a Survey on Inclusion of Health Disparities, Cultural Competence, and Health Literacy Content in Their Curriculums ${ }^{\text {a }}$

\begin{tabular}{|c|c|c|}
\hline Variable & $\begin{array}{c}\text { US Colleges and Schools } \\
(\mathrm{n}=72) \\
\text { No. }(\%) \\
\end{array}$ & $\begin{array}{c}\text { Canadian Colleges and } \\
\text { Schools }(\mathrm{n}=8) \\
\text { No. }(\%) \\
\end{array}$ \\
\hline \multicolumn{3}{|l|}{ Type of Institution } \\
\hline Private & $41(56.9)$ & 0 \\
\hline Public & $31(43.1)$ & $8(100.0)$ \\
\hline \multicolumn{3}{|l|}{ Accreditation Status } \\
\hline Accredited & $67(93.1)$ & $8(100.0)$ \\
\hline Candidate Status & $5(6.9)$ & 0 \\
\hline \multicolumn{3}{|l|}{ Designation } \\
\hline None & $52(72.2)$ & $8(100.0)$ \\
\hline Land-Trust & $10(13.9)$ & 0 \\
\hline $\mathrm{HBCU}$ & $4(5.6)$ & 0 \\
\hline Hispanic-Serving Institution & $4(5.6)$ & 0 \\
\hline Other $^{\mathrm{b}}$ & $3(4.2)$ & 0 \\
\hline \multicolumn{3}{|l|}{ Faith-Based } \\
\hline Yes & $13(18.1)$ & 0 \\
\hline No & $59(81.9)$ & $8(100.0)$ \\
\hline \multicolumn{3}{|l|}{$\begin{array}{l}\text { Faculty Involvement in Teaching HDCC and } \\
\text { Health Literacy Topics }{ }^{\mathrm{c}}\end{array}$} \\
\hline One faculty member & $4(6.3)$ & 0 \\
\hline A few key faculty $(<5 \%)$ & $27(42.9)$ & $6(75.0)$ \\
\hline A core group of faculty $(5-25 \%)$ & $21(33.3)$ & $1(12.5)$ \\
\hline A moderate amount of faculty $(26-50 \%)$ & $7(11.1)$ & $1(12.5)$ \\
\hline More than half of faculty $(>50 \%)$ & $4(6.4)$ & 0 \\
\hline
\end{tabular}


Table 2. Content and Delivery in Pre-APPE, IPPE, and APPE Curriculum ${ }^{\mathrm{a}}$

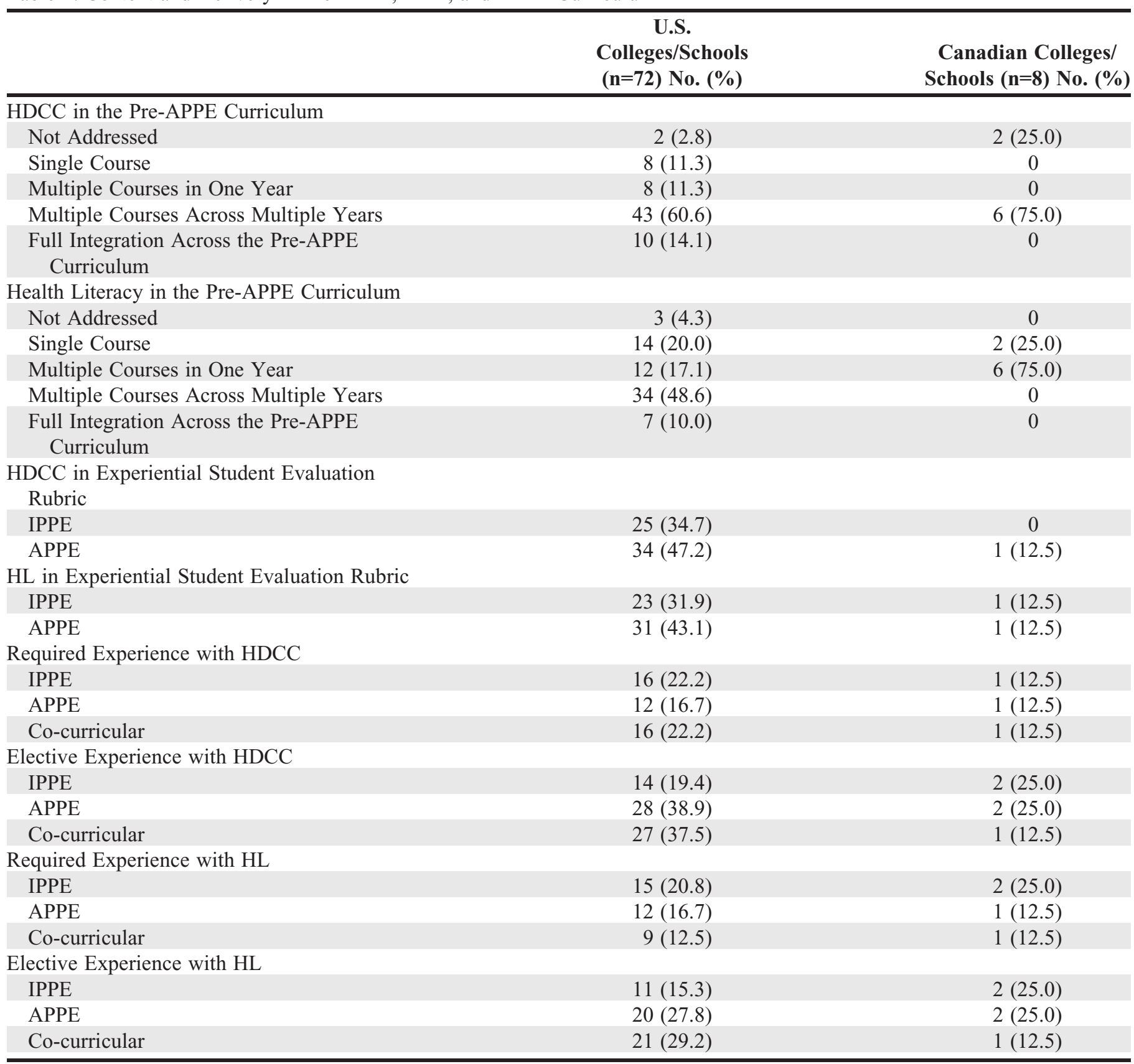

Abbreviations: $\mathrm{HDCC}=$ health disparities and cultural competency, APPE=advanced pharmacy practice experiential

${ }^{a}$ Survey responses were not forced, allowing institutions to skip questions as desired. The percentage has been adjusted for the percentage of schools who responded to the question

literacy concepts (with the exception of tools to measure health literacy); however, there was variation in the level taught. The scope of the problem of health literacy was taught at the reinforcement or mastery level, tools to measure patient health literacy only was taught at the introductory level, and assessing the suitability of written materials was taught at the introductory or reinforcement level. The plain language and clear communication items covered all levels. (Table 3).
Active-learning approaches were used in most US pharmacy schools to teach HDCC and HL topics (Table 4). In Canada, active learning was more frequently used in teaching HL than HDCC (50\% HL vs $25 \%$ HDCC). Frequently $(40 \%$ or more of programs) used activelearning approaches for HDCC included case studies/ video case studies, reflective writing/surveys, objective structured clinical examinations (OSCEs), role-plays, and cultural simulation games and activities. For HL, nearly 
American Journal of Pharmaceutical Education 2021; 85 (1) Article 8200.

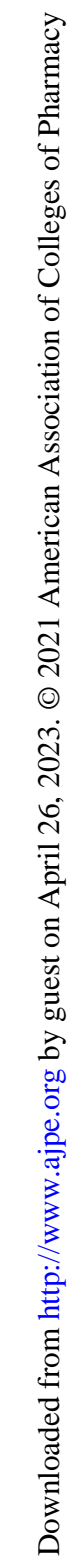

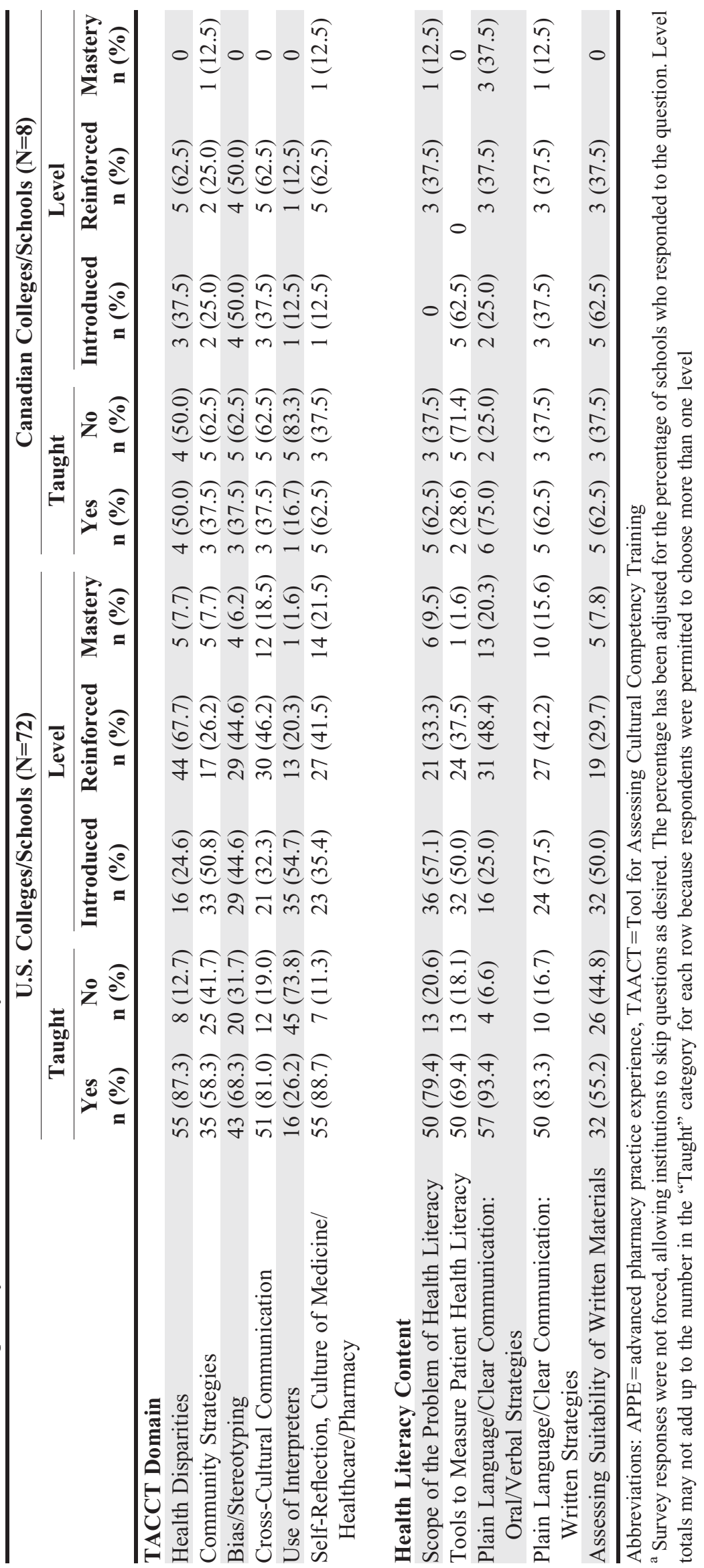


American Journal of Pharmaceutical Education 2021; 85 (1) Article 8200.

Table 4. Active Learning Approaches in the Pre-APPE Curriculum ${ }^{\mathrm{a}}$

\begin{tabular}{|c|c|c|}
\hline & $\begin{array}{l}\text { U.S. Colleges/Schools } \\
\quad(\mathrm{N}=72) \text { n }(\%)\end{array}$ & $\begin{array}{c}\text { Canadian Colleges/Schools } \\
(\mathrm{N}=8) \text { n }(\%)\end{array}$ \\
\hline \multicolumn{3}{|l|}{$\begin{array}{l}\text { Use Active Learning to Teach HDCC and Health } \\
\text { Literacy }\end{array}$} \\
\hline Yes, both HDCC and Health Literacy & $50(78.1)$ & $1(12.5)$ \\
\hline Yes, HDCC & $8(12.5)$ & $2(25.0)$ \\
\hline Yes, Health Literacy & $3(4.7)$ & $4(50.0)$ \\
\hline No & $3(4.7)$ & $1(12.5)$ \\
\hline \multicolumn{3}{|l|}{ HDCC Active Learning Approaches } \\
\hline Case studies or video case studies & $54(75.0)$ & $4(50.0)$ \\
\hline Reflective writing or surveys & $42(58.3)$ & $3(37.5)$ \\
\hline OSCE or virtual/standardized patients & $31(43.1)$ & $3(37.5)$ \\
\hline Role-play or role-reversal exercise & $29(40.3)$ & $3(37.5)$ \\
\hline Cultural simulation game or activity & $29(40.3)$ & $1(12.5)$ \\
\hline Seminar series, forum, or panel discussion & $23(31.9)$ & $2(25.0)$ \\
\hline Global experience & $18(25.0)$ & 0 \\
\hline Research paper or presentation & 17 (23.6) & $1(12.5)$ \\
\hline $\begin{array}{l}\text { Community interview of a different cultural } \\
\text { group or member }\end{array}$ & $16(22.2)$ & $2(25.0)$ \\
\hline Book clubs & $7(9.7)$ & 0 \\
\hline UCSF Toolbox & $6(8.3)$ & 0 \\
\hline $\begin{array}{l}\text { Group (large and small) discussion, Team-Based } \\
\text { Learning }\end{array}$ & $4(5.6)$ & 0 \\
\hline Community service or outreach & $2(2.8)$ & 0 \\
\hline Other, specified ${ }^{\mathrm{b}}$ & $7(9.7)$ & $2(25.0)$ \\
\hline \multicolumn{3}{|l|}{ Health Literacy Active Learning Approaches } \\
\hline Case studies or video case studies & $37(51.4)$ & $1(12.5)$ \\
\hline $\begin{array}{l}\text { Simplifying or creating a simplified patient } \\
\text { material }\end{array}$ & $34(47.2)$ & $6(75.0)$ \\
\hline Reflective writing or self-evaluation of literacy & $27(37.5)$ & $2(25.0)$ \\
\hline Role-play or role-reversal exercise & $26(36.1)$ & $3(37.5)$ \\
\hline OSCE or virtual/standardized patients & $24(33.3)$ & $3(37.5)$ \\
\hline Simulation game or activity & $21(29.2)$ & $2(25.0)$ \\
\hline Seminar series, forum, or panel discussion & $9(12.5)$ & $1(12.5)$ \\
\hline Other, specified $^{c}$ & $5(6.9)$ & 0 \\
\hline
\end{tabular}

Abbreviations: APPE $=$ advanced pharmacy practice experience, $\mathrm{HDCC}=$ health disparities and cultural competency,

$\mathrm{OSCE}=$ observed structured clinical examination, $\mathrm{UCSF}=$ University of California San Francisco

${ }^{a}$ Survey responses were not forced, allowing institutions to skip questions as desired. The percentage has been adjusted for the percentage of schools who responded to the question

${ }^{\mathrm{b}}$ Other responses included: health communication campaign development, interprofessional education group activities (eg, experiencing diversity in the classroom), educational material development, health equity team project, integration of HDCC concepts into drug information questions, cultural showcase, hip hop, Indigenous blanket exercise (Canadian program for all citizens)

${ }^{\mathrm{c}}$ Other responses included: participation in outreach health fairs, presentation of materials to public in a health fair, team-based learning, health literacy assessment of a pharmacy using the Agency for Healthcare Research and Quality tool, evaluate a medication information piece written in another language

half of the US programs indicated that they used case studies along with simplifying or creating educational materials $(51.4 \%$ and $47.2 \%$, respectively). Common patient populations included in the curricula of $>60 \%$ of US and Canadian schools were: racial/ethnic groups, poverty/low-income, sexuality and gender issues, religion/spirituality, mental illness, disabilities, uninsured/ underinsured, and older adults (Table 5).
In the United States, HDCC and HL concepts were included in approximately one-third of IPPE and APPE evaluations (Table 2). Although mostly taught in elective APPE and elective co-curricular experiences, some schools $(<23 \%)$ included HDCC and HL in required IPPE, APPE, or co-curricular experiences. In Canada, $<25 \%$ of schools included HDCC or HL as required or elective IPPE or APPE experiences. Only one institution 
American Journal of Pharmaceutical Education 2021; 85 (1) Article 8200.

Table 5. HDCC and Health Literacy Populations Covered in the Pre-APPE Curriculum ${ }^{\mathrm{a}}$

\begin{tabular}{lcc}
\hline & $\begin{array}{c}\text { U.S. Colleges/Schools } \\
(\mathbf{n}=\mathbf{7 2}) \\
\text { No. }(\mathbf{\%})\end{array}$ & $\begin{array}{c}\text { Canadian Colleges/Schools } \\
(\mathbf{n}=\mathbf{8}) \\
\text { No. }(\mathbf{\%})\end{array}$ \\
\hline Racial/ethnic groups & $57(79.2)$ & $6(75.0)$ \\
Poverty/low-income & $55(76.4)$ & $6(75.0)$ \\
$\begin{array}{l}\text { Issues of sexuality, sexual orientation, gender } \\
\quad \text { identity, gender expression }\end{array}$ & $49(68.1)$ & $6(75.0)$ \\
$\begin{array}{l}\text { Religious background/faith/spirituality (specific } \\
\quad \text { religious groups) }\end{array}$ & $49(68.1)$ & $5(62.5)$ \\
Mental illness & $49(68.1)$ & $8(100.0)$ \\
Patients with disabilities & $48(66.7)$ & $7(87.5)$ \\
Uninsured/underinsured & $48(66.7)$ & $6(75.0)$ \\
Older adults & $45(62.5)$ & $6(75.0)$ \\
Rural populations in medically underserved & $43(59.7)$ & $4(50.0)$ \\
$\quad$ areas & & $4(50.0)$ \\
Homeless & $39(54.2)$ & $4(50.0)$ \\
Immigrants & $37(51.4)$ & $4(50.0)$ \\
Obese & $26(36.1)$ & $3(37.5)$ \\
Refugees & $25(34.7)$ & $0(0.0)$ \\
\hline Other, specified & $4(5.6)$ & \\
\hline
\end{tabular}

Abbreviations: $\mathrm{HDCC}=$ health disparities and cultural competency, APPE $=$ advanced pharmacy practice experience

${ }^{a}$ Survey responses were not forced, allowing institutions to skip questions as desired. The percentage has been adjusted for the percentage of schools who responded to the question

${ }^{\mathrm{b}}$ Substance use/dependence/recovering populations, maternal/child health, patients with specific diseases (eg, HIV/AIDS)

included HDCC or HL in IPPE/APPE evaluations, cocurriculum experiences (required or elective), or required APPE experiences (Table 2).

Institutions in the United States most commonly collected data regarding patient populations and health beliefs encountered (IPPEs, $\mathrm{n}=17,33.3 \%$; APPEs, $\mathrm{n}=21,40.4 \%$ ), but rarely collected other information, such as the percentage of patients from a certain ethnic or patient group $(n=2,2.8 \%)$ or whether students had experienced working with any diverse populations $(n=1$, $1.4 \%$ ). One program in Canada gathered information about patient populations or health beliefs encountered during APPEs.

In total, approximately one-fourth of US institutions reported providing faculty professional development related to HDCC $(n=4,7.1 \%)$ and HDCC and HL $(n=11$, 19.6\%). Institutional interests in pursuing advanced credentialing in HDCC were positive (yes, $\mathrm{n}=22,34.9 \%$; maybe, $n=37,58.7 \%$ ). No Canadian institutions provided professional development on HDCC or HL concepts; however, almost two-thirds of the responding institutions $(n=5,62.5 \%)$ were interested in pursuing advanced credentialing options.

Differences between $\mathrm{C} / \mathrm{SOP}$ characteristics were examined. No significant differences were found among the responding institutions after stratification by type of institution (public vs private) in the use of active-learning $(p=.38)$ and level of faculty involvement $(p=.18)$. There also were no differences in the level of faculty involvement by designation $(p=.45)$. No significant differences were found in the use of active learning by level of faculty involvement $(p=.92)$, designation $(p=.99)$, or faith-based/not faith-based ( $p=.247)$. Faith-based institutions in the United States had significantly higher percentages of faculty involvement $(p=.04$; see footnote in Table 1).

\section{DISCUSSION}

This is the first and largest evaluation of the inclusion of health disparities and cultural competence and health literacy concepts since the assessment by Onyoni and Ives, which focused on the inclusion of cultural competency in the mission, curriculum, and experiential programs of schools and colleges of pharmacy. ${ }^{14}$ In that study, most respondents included cultural competency in some form, primarily in didactic and case-based education, but perceived a need to expand education in the curriculum. ${ }^{14}$ Since 2007, health disparities and cultural competence content and health literacy content has been included in multiple courses and includes many key topics. While there is still much ground to cover and training to enhance student learning, significant progress has occurred. 


\section{American Journal of Pharmaceutical Education 2021; 85 (1) Article 8200.}

More than half of US schools participated, and the survey responses were fairly representative of the US Academy, with both private (57\%) and public (43\%) institutions responding. According to AACP's Vital Statistics, $52 \%$ of schools are private and $48 \%$ are public. ${ }^{21}$ There also was a high response rate among Canadian schools (80\%). Therefore, the selection bias at the school level was minimized in our study, which improves generalizability. This study revealed that most schools addressed health disparities and cultural competence content (United States, 97.2\%, Canada, 75.0\%,) and health literacy (United States, 95.7\%; Canada, 100\%), but few schools included these concepts throughout the entire curriculum, particularly when including experiential education, and training rarely achieved mastery level. Health disparities and cultural competence received more reinforcement than health literacy. Further, results revealed limited integration within the experiential curriculum with few faculty members responsible for delivering the content. Except for plain language/clear communication topics (verbal or written), other health literacy topics were taught at introductory or reinforcement levels. Given the value and significance of clear communication, a greater number of schools should strive for higher levels of achievement (mastery) by offering opportunities to incorporate health literacytailored communication principles in IPPE, APPE, and co-curricular areas. Also, given the health disparities and cultural competence issues and health literacy issues faced by some population groups, such as the elderly and those who are obese, it was surprising that US schools covered these population groups to a lesser extent in the pre-APPE curriculum. However, this was not the case in Canadian schools. One explanation may be that population groups, such as those who are elderly or obese, may have been accounted for in other categories (eg, elderly patient who is a racial or ethnic minority).

One area of focus for schools should be the inclusion of how to work with interpreters. A small portion of schools $(26.2 \%$, US; $16.7 \%$, Canada) included such content in their curricula, yet student pharmacists and pharmacists frequently engage with patients whose preferred language is different from their own. In Canada, $14.5 \%$ of residents speak an unofficial language (ie, not English or French) at home, and $22.9 \%$ have a nonofficial language as their mother tongue. ${ }^{22}$ With $23 \%$ of US residents speaking English not well or not very well ${ }^{23}$ and $20.7 \%$ speaking a language other than English at home ${ }^{24}$ pharmacists should be skilled in working with medical interpreters to communicate effectively with their patients. The 2013 American College of Clinical
Pharmacy White Paper recommended that two student learning objectives be included in pharmacy curricula: "Identify patients who would benefit from an interpreter and work efficiently with an interpreter." ${ }^{, 10}$ Some schools have included interpreters during APPE experiences, ${ }^{25}$ but limited literature is available regarding inclusion of these concepts. Given the availability of various interpreter services, such training could be an asset in educating student pharmacists.

Curricular integration may be of three types: horizontal integration where multiple disciplines teach and reinforce concepts; vertical integration where concepts are repeated throughout the curriculum and in the experiential setting; and spiral integration where concepts are not only readdressed throughout the curriculum, but each time the concepts have greater complexity. ${ }^{26}$ We would argue that curricular integration of health disparities and cultural competence content and health literacy content should include both horizontal and vertical, wherein these concepts are taught in multiple courses over multiple years. While increasing complexity should be an ideal aim for programs, it would require substantial coordination and would entail faculty development to match teaching skills to the desired level of complexity. Many schools indicated interest in options for advanced credentialing in this area; thus, there could be an opportunity for the Academy to provide resources to support faculty members in teaching this content.

Given that cultural sensitivity and patient communication are included in ACPE Standard $3,{ }^{12}$ the inclusion of health disparities and cultural competence concepts and health literacy concepts in the co-curriculum would serve to further augment student learning of these concepts in the didactic and experiential curriculum as well as be an ideal location to further vertical integration efforts. Integration efforts in the academic pharmacy literature highlight examples within an academic year across courses and include both didactic and lab-based coursework ${ }^{27}$ or didactic, laboratory, and experiential coursework. ${ }^{17}$ Some institutions have intentionally expanded content throughout the curriculum by integrating across multiple didactic courses in each academic year with skills laboratory integration ${ }^{28}$ or with skills laboratory and IPPE integration. ${ }^{29}$

There are limitations to this work that must be considered. Although the "pre-APPE" definition was provided at the beginning of the instrument, some respondents may have interpreted the term to include IPPE. Items that specifically included the term IPPE may have helped to minimize variability in interpretation. Despite the survey containing only 16 items, survey fatigue may have occurred as many items required retrieval 


\section{American Journal of Pharmaceutical Education 2021; 85 (1) Article 8200.}

of information to provide an adequate response. When distributing the survey, investigators identified key faculty members. However, in cases where no key faculty member was identified, the survey was sent to the school's assessment leaders. Assessment leads may not have known as much information about health disparities and cultural competence content and health literacy integration as key faculty members who teach this content. The process by which respondents completed this instrument is unknown, eg, whether they organized faculty members for a more complete response or made assumptions independently. Credentials or areas of expertise of faculty members teaching health disparities and cultural competence content and health literacy were not requested. In some of the Canadian schools, there was a transition to the PharmD program, which was mandated as the entryto-practice degree for 2020. At the time of the survey, some participants may have been referencing their completed Bachelor of Science degree, while others had transitioned completely to the PharmD curriculum. Finally, there were no restrictions placed on the survey to ensure consistency in answers. For example, respondents could have indicated that their school did not teach an area but later indicated that the area was taught at the reinforcement level.

\section{CONCLUSION}

Pharmacy programs in Canada and the United States appear to have varying levels of content coverage related to health disparities and cultural competence and health literacy. Less content is required and implemented within experiential programs and co-curriculum, despite the AFPC Outcomes emphasizing the TRC and ACPE Standards 2016 requiring inclusion of cultural sensitivity. Barriers exist for institutions to substantially integrate these topics, which are likely multi-factorial and go beyond the scope of this survey. Depth of content remains primarily at the introductory or reinforcement level rather than mastery. Opportunities remain to expand and apply information on health disparities and cultural competence content and health literacy content, particularly outside the didactic curriculum, as well as identify barriers to integration of this content across universities.

\section{REFERENCES}

1. Colby SL, Ortman JM. Projections of the size and composition of the U.S. population: 2014 to 2060, Current population reports, P251143. 2015. https://www.census.gov/content/dam/Census/library/ publications/2015/demo/p25-1143.pdf. Accessed December 22, 2020.

2. Department of Health and Human Services. HHS action plan to reduce racial and ethnic health disparities: a nation free of disparities in health and health care. 2011. https://www.minorityhealth.hhs.gov/
npa/files/Plans/HHS/HHS_Plan_complete.pdf. Accessed

Decemmber 22, 2020.

3. Berkman ND, Sheridan SL, Donahue KE, et al. Health literacy interventions and outcomes: An updated systematic review.

Rockville, MD: Agency for Healthcare Research and Quality. 2011. 4. Institute of Medicine. Health literacy: A prescription to end confusion. National Academy of Sciences; 2004.

5. Canadian Association of Chiefs of Police. Literacy and policing in Canada: Target crime with literacy. 2009. http://policeabc.ca/files/ factsheets_englishPDFs/Literacy_factsheets_eng.pdf. Accessed December 22, 2020.

6. National Center for Education Statistics. National assessment of adult literacy (NAAL): A nationally representative and continuing assessment of English language literary skills of American Adults. 2003. https://nces.ed.gov/naal/index.asp. Accessed December 22, 2020.

7. Trudeau J. Minister of Health mandate letter. 2019. https:// pm.gc.ca/en/mandate-letters/2019/12/13/minister-health-mandateletter. Accessed December 22, 2020.

8. Truth. and Reconciliation Commission of Canada. Truth and reconciliation commission of Canada: Calls to action. 2015. http:// trc.ca/assets/pdf/Calls_to_Action_English2.pdf. Accessed December 22, 2020 .

9. O'Connell MB, Jackson AN, Karaoui LR, et al. Cultural competency in health care and its implications for pharmacy part 3B: Emphasis on pharmacy education policy, procedures, and climate. Pharmacotherapy. 2013;33(12):368-381.

10. O'Connell MB, Rodriguez de Bittner M, Poirier TI, et al. Cultural competency in health care and its implications for pharmact Part 3A: Emphasis on pharmacy education, curriculums, and future directions. Pharmacotherapy. 2013;33(12):347-367.

11. Association of Faculties of Pharmacy of Canada (AFPC). AFPC educational outcomes for first professional degree programs in Canada 2017. 2017. https://www.afpc.info/system/files/public/ AFPC-Educational\%20Outcomes\%202017_final\%20Jun2017.pdf. Accessed December 22, 2020.

12. Accreditation Council for Pharmacy Education. Accreditation standards and key elements for the professional program in pharmacy leading to the Doctor of Pharmacy degree: "Standards 2016". 2015. https://www.acpe-accredit.org/pdf/Standards2016FINAL.pdf. Accessed December 22, 2020.

13. Medina MS, Plaza CM, Stowe CD, et al. Center for the Advancement of Pharmacy Education 2013 educational outcomes. Am J Pharm Educ. 2013;77(8):162.

14. Onyoni EM, Ives TJ. Assessing implementation of cultural competency content in the curricula of colleges of pharmacy in the United States and Canada. Am J Pharm Educ. 2007;71(2):24. 15. Devraj R, Butler LM, Gupchup GV, Poirier TI. Active-learning strategies to develop health literacy knowledge and skills. Am J Pharm Educ. 2010;74(8):137.

16. Chen AMH. Impact of health literacy assignment on student pharmacist learning. Res Social Adm Pharm. 2013;9(3):531-541. 17. Cailor SM, Chen AMH. Immediate and longitudinal effects of incorporating health literacy and cultural competency into a yearlong pharmacy curriculum. Curr Pharm Teach Learn. 2015;7(3):292-301. 18. Lie D, Boker J, Cleveland E. Using the Tool for Assessing Cultural Competence Training (TACCT) to measure faculty and medical student perceptions of cultural competence instruction in the first three years of the curriculum. Acad Med. 2006;81(6):557-564. 19. Lie DA, Boker J, Crandall S, et al. Revising the Tool for Assessing the Cultural Competence Training (TACCT) for 


\section{American Journal of Pharmaceutical Education 2021; 85 (1) Article 8200.}

curriculum evaluation: findings derived from seven US schools and expert consensus. Med Educ Online. 2008;13:11. doi: 10.3885/ meo.2008.Res00272

20. Dillman DA, Smyth JD, Christian LM. Internet, phone, mail, and mixed-mode surveys: The tailored design method. John Wiley \& Sons; 2014.

21. American Association of Colleges of Pharmacy. Academic pharmacy's vital statistics. 2019. https://www.aacp.org/article/ academic-pharmacys-vital-statistics. Accessed December 22, 2020. 22. Statistics Canada. Linguistic diversity and multilingualism in Canadian homes. 2017. https://www12.statcan.gc.ca/censusrecensement/2016/as-sa/98-200-x/2016010/98-200-x2016010eng.cfm. Accessed December 22, 2020.

23. Ryan C. Language use in the United States, 2013: American Community Survey Reports. 2013. https://www2.census.gov/library/ publications/2013/acs/acs-22/acs-22.pdf. Accessed December 22, 2020.

24. United States Census Bureau. Detailed languages spoken at home and ability to speak English for the population 5 years and over:
2009-2013. 2015. https://www.census.gov/data/tables/2013/demo/ 2009-2013-lang-tables.html. Accessed December 22, 2020.

25. Haack S.. Engaging pharmacy students with diverse patient populations to improve cultural competence. Am J Pharm Educ. 2008;72(5):124.

26. Pearson ML, Hubball HT. Curricular integration in pharmacy education. Am J Pharm Educ. 2012;76(10):204.

27. Okoro O, Odedine F, Smith WT. Determining the sufficiency of cultural competence instruction in pharmacy school curriculum. Am J Pharm Educ. 2015;79(4):150.

28. Haack S, Phillips CD. Teaching cultural competency through a pharmacy skills and applications course series. Am J Pharm Educ. 2012;76(2):27.

29. Chen AMH, Cailor S, Wicker E, Harper N, Franz T, Pahl B. Impact of integrating health literacy and cultural competency concepts across the curriculum. Am J Pharm Educ. 2020;84(10):7764. 30. Agency for Healthcare Research and Quality. AHRQ pharmacy health literacy center. July 2017. https:/www.ahrq.gov/healthliteracy/pharmhealthlit/index.html. Accessed December 22, 2020. 